\title{
Haematological Studies in the Dogs Having Long Bone Fractures Treated with Plate Rod Construct
}

\author{
G. U. Yadav*, L. B. Sarkate and D. U. Lokhande \\ Department of Surgery and Radiology, Mumbai Veterinary College Parel \\ Mumbai-400012, India \\ Maharashtra Animlal and Fishery University Nagpur, India \\ *Corresponding author
}

Keywords

Bone fractures, femur and humerus, plate rod

Article Info

Accepted:

18 March 2021

Available Online:

10 April 2021

\section{A B S T R A C T}

Eight cases of long bone fractures of femur and humerus were treated with plate rod construct, whereas, the preoperative anterio- posterior (AP) and lateral radiographs $(\mathrm{L})$ of fractured limb were taken. Diazepam $(0.2 \mathrm{mg} / \mathrm{kg})$ was administered intravenously, 10 minutes prior to induction of general anaesthesia with thiopentone sodium $(15 \mathrm{mg} / \mathrm{kg}$ body weight) followed by maintained with isoflurane $(1.5-2.0 \%)$. the plate rod construct was applied by craniolateral approach in case of humerus and femur bone in dogs. The mean haematological values of haemoglobin, Packed Cell Volume and Platelates before surgery and on $7^{\text {th }}$ day, $21^{\text {st }}$ day, $30^{\text {th }}$ day, $45^{\text {th }}$ day and $60^{\text {th }}$ day of surgery did not significantly differ within group. The mean alkaline phosphatase increased up to 45 days and subsequently decreased at 60 days. The mean cortisol values were higher before surgery, but the non-significant decrease in mean serum cortisol values were seen during fracture healing period and they returned to normal on 60 days.

\section{Introduction}

Plate rod construct is commonly used in canine fracture repair. It provides the double strength to the bone for fracture stabilization. The other advantage of this technique is that the pin used in the combination increases stiffness and rigidity which helps in healing of fracture by plate protection from bending. The combination of plate rod is acting as two bims (Hulse et al., 1997). The advantages of this technique are yet to be popularize in Veterinary practice hence very few people are using this technique

\section{Materials and Methods}

The present study was conducted on eight clinical cases in canine having fractures of long bones, presented to the Department of Surgery, Mumbai Veterinary College, Parel and Bai Sakarbai Dinshaw Petit Hospital for 
Animals, affiliated animal hospital with the College. The preoperative radiographs of fractured limb in anterio-posterior and lateral position were taken. All the orthopaedic surgeries were performed under general anaesthesia using isoflurane inhalation anaesthesia by giving atropine sulphate $(0.04$ $\mathrm{mg} / \mathrm{kg})$ and dexamethasone $(0.5 \mathrm{mg} / \mathrm{kg})$ subcutaneously half an hour prior to surgery. Diazepam $(0.2 \mathrm{mg} / \mathrm{kg})$ was administered intravenously, 10 minutes prior to induction of general anaesthesia with Thiopentone sodium $(15 \mathrm{mg} / \mathrm{kg})$. Following smooth induction of anaesthesia, the surgical anaesthesia was maintained throughout the duration of surgery using isoflurane (1.5 - $2.0 \%)$ inhalation anaesthesia. In this group, the plate rod construct was used for the repair of femoral and humeral fractures in dogs. After anatomical dissection the intramedullary pin of approximately $25-40 \%$ of the diameter of the medullary canal was selected. The Steinman pin or K-wire of $2 \mathrm{~mm}$ or $2.5 \mathrm{~mm}$ size pin was inserted in a retrograde fashion till it comes out at the top of the skin surface and then the pin was moved down into the distal femoral or humoral fragment. The stainless steel bone plate of $2 \mathrm{~mm}$ thick and appropriate length with $2.7-3.5 \mathrm{~mm}$ hole (DCP) size was selected, and applied on the tensile surface of the bone by fixation of bicortical screws.

\section{Haematological Parameters}

In all the cases of all groups the following parameters were studied,

\section{Haematology}

In all the animals the blood samples of each dog were collected in two bottles by using 22 gauge needle and $5 \mathrm{ml}$ disposable sterile syringe from cephalic or saphenous vein, of which $2 \mathrm{ml}$ of blood was collected in EDTA vial and $3 \mathrm{ml}$ blood sample was collected for serum (in non EDTA vials). The samples were analyzed for Haemoglobin, Packed cell volume, White Blood Cell Count and Platlates on $7^{\text {th }}$ day and on $21^{\text {st }}, 45^{\text {th }}$ day and $60^{\text {th }}$ day of surgery.

\section{Biochemical study}

Alkaline phosphatise and cortisol levels were estimated before surgery as well as on $7^{\text {th }}, 21^{\text {st }}$, $30^{\text {th }}, 45^{\text {th }}$ and $60^{\text {th }}$ day post operatively.

\section{Results and Discussion}

The pre-operative anterio-posterior (AP) and lateral radiographs (L) of affected limb were taken in each case, for the diagnosis of type of fracture following light sedation. Each radiograph was evaluated for the type of fracture as well as for damage to the surrounding tissue. Pre-operative radiography had given an idea about the choice of technique to be used for the repair of fracture and thus it helped the surgeon to plan the surgery in a systemic way for better outcome. Bhalerao (2010), Coutinho (2012) and Chavan (2013) performed preoperative radiography for the evaluation of fracture as well as for selecting the proper technique of fracture repair. In the present study, simple, comminuted and oblique fractures in hyperactive animals were operated with plate rod construct. Bhalerao (2010) used plate rod construct in similar types of fractures.

Proper care was taken to withhold water for 12 hours and food for 18 hours prior to surgery, so as to prevent untoward complications during induction and maintenance of anaesthesia during surgery. Kaur (2011) advised withholding of food for 12 hours and water for 4 hours before performing surgery.

All the orthopaedic surgeries in all the groups were performed under general anaesthesia using isoflurane. Pre-medication with atropine 
sulphate@ 0.04 mg/kg and dexamethasone @ $0.5 \mathrm{mg} / \mathrm{kg}$ body weight subcutaneously followed by intravenous injection of Diazepam $(0.2 \mathrm{mg} / \mathrm{kg})$ provided smooth sedation in all the dogs. General anaesthesia induced by intravenous injection of thiopentone sodium was smooth in all the dogs. Following smooth induction, the surgical anaesthesia was maintained with isoflurane (1.5 - $2.0 \%)$ anaesthesia. Gupta (2005), Bhagat (2009) reported successful use of ketamine and midazolam combination for induction and maintenance of anaesthesia during orthopaedic procedures in canine.

For fractures of humerus, and femur was used. This approach was found suitable for humerus and there was sufficient exposure of muscles and bone. This made it possible to perform the operative procedure, without any difficulty. The pin insertion in the bone was done properly without any complication. The bone plate placed on cranio-lateral tensile surface of bone had given full rigidity to the assembly in the fixation of fractures of humerus and there was no any tension over the muscle and skin sutures.

The cranio-lateral approach provided the sufficient space for exposure of muscles and bones. The insertion of pin was performed without any complications. Guillemot et al., (2002) reported that, if the pin is inserted in retrograde fashion, there are chances of injury to sciatic nerve.

In present study the stainless steel bone plate of $2.7-3.5 \mathrm{~mm}$ size and of appropriate length and proper size screws were used for the fixation of plate, while intramedullary pin or K-wire of 25 to $40 \%$ of the diameter of medullary canal $(2.0 \mathrm{~mm}-2.5 \mathrm{~mm})$ was used for intramedullary fixation. Bhalerao (2010) used the similar types of intramedullary pins and bone plates for the repair of canine long bone fractures. The intramedullary pin or $\mathrm{K}$ - wire of 2.0 - $2.5 \mathrm{~mm}$ diameter $(25-40 \%)$ was inserted in retrograde fashion till it come out at the top of the skin surface and then the pin was moved down through normo-grade fixation into the distal femoral or humoral fragment. The application of low man's clamp and bone plate was very much essential for proper insertion of intramedullary pin into the distal fractured fragments. Fixation of bone plate with at least two screws near the fracture and one in corner hole of the plate on either side was done without difficulty. Initially placement of bicortical screws to each corner of hole of plate requires practical experience to avoid its entry at site of intramedullary pin. The combination of intramedullary pin / Kwire and bone plate provided rigid fixation and given strength to plate rod assembly. Ferry et al., (2000) and Roe (2003) stated that the size of intramedullary pin should be 30 $40 \%$ of size of medullary cavity.

\section{Haematology}

In all the animals the blood samples of each dog were collected in two bottles by using 22 gauge needle and $5 \mathrm{ml}$ disposable sterile syringe from cephalic or saphenous vein, of which $2 \mathrm{ml}$ of blood was collected in EDTA vial and $3 \mathrm{ml}$ blood sample was collected for serum (in non EDTA vials).

\section{Haemoglobin}

The mean haemoglobin levels (gm\%) before surgery, 7 th day, $21^{\text {st }}$ day, $30^{\text {th }}$ days, $45^{\text {th }}$ days and $60^{\text {th }}$ day of surgery did not differ significantly within the group. Similar findings were reported by Patil (2007), Bhalerao (2010), Coutinho (2012) and Rajhans (2013). All the dogs remained healthy throughout the period of fracture healing. Ayappan et al., (2011) reported that the haematological parameters were within the normal range before and after surgery in a dog operated for plate rod construct. 
Table.1 Haemoglobin values (gm \%) and their mean

\begin{tabular}{|l|c|c|c|c|c|}
\hline \multicolumn{1}{|c|}{ Hb } & Before & 7 Days & 21 Days & 45 Days & 60 Days \\
\hline Case No.1 & 16.7 & 16.1 & 14.9 & 15.8 & 13.6 \\
\hline Case No. 2 & 13.1 & 14.3 & 15.2 & 13.4 & 12.8 \\
\hline Case No. 3 & 15.5 & 16.3 & 12.1 & 13.2 & 15.6 \\
\hline Case No. 4 & 12.9 & 14.1 & 15.6 & 16.2 & 14.9 \\
\hline Case No. 5 & 13.1 & 12.6 & 15.1 & 14.2 & 13.4 \\
\hline Case No. 6 & 13.6 & 12.0 & 13.3 & 14.2 & 15.3 \\
\hline Case No. 7 & 13.6 & 14.9 & 12.6 & 12.5 & 12.8 \\
\hline Case No. 8 & 13.2 & 13.2 & 12.8 & 14.2 & 14.3 \\
\hline Mean & $\mathbf{1 3 . 9 6}$ & $\mathbf{1 4 . 1 8}$ & $\mathbf{1 3 . 9 5}$ & $\mathbf{1 4 . 2}$ & $\mathbf{1 4 . 1}$ \\
\hline S.E \pm & $\mathbf{0 . 4 8}$ & $\mathbf{0 . 5 4}$ & $\mathbf{0 . 4 9}$ & $\mathbf{0 . 4 4}$ & $\mathbf{0 . 3 9}$ \\
\hline
\end{tabular}

Table.2 The packed cell volume values in the present study

\begin{tabular}{|c|c|c|c|c|c|}
\hline PCV & Before & 7 Days & 21 Days & 45 Days & 60 Days \\
\hline Case No.1 & 45.4 & 48.1 & 42.1 & 45.3 & 40.2 \\
\hline Case No. 2 & 39.2 & 42.6 & 45.8 & 39.1 & 38.1 \\
\hline Case No. 3 & 45.9 & 48.1 & 37.2 & 39.2 & 45.3 \\
\hline Case No. 4 & 40.2 & 43.7 & 47.1 & 50.6 & 42.6 \\
\hline Case No. 5 & 41.7 & 37.8 & 44.5 & 45.9 & 42. \\
\hline Case No. 6 & 42.9 & 42.1 & 43.2 & 42.3 & 45.2 \\
\hline Case No. 7 & 42.2 & 42.3 & 43.8 & 45.3 & 45.6 \\
\hline Case No. 8 & 43.3 & 42.4 & 42.9 & 45.6 & 42.6 \\
\hline Mean & $\mathbf{4 2 . 6}$ & $\mathbf{4 3 . 3 8}$ & $\mathbf{4 3 . 3 3}$ & $\mathbf{4 4 . 2}$ & $\mathbf{4 2 . 8}$ \\
\hline S.E \pm & $\mathbf{0 . 8 1}$ & $\mathbf{1 . 1 9}$ & $\mathbf{1 . 0 4}$ & $\mathbf{1 . 3 6}$ & $\mathbf{0 . 9 3}$ \\
\hline
\end{tabular}

Table.3 Total White Blood Cells (WBC): The total WBC values are given in following table

\begin{tabular}{|c|c|c|c|c|c|}
\hline WBC & Before & 7 Days & 21 Days & 45 Days & 60 Days \\
\hline Case No.1 & 8500 & 12000 & 9000 & 12000 & 13200 \\
\hline Case No. 2 & 9300 & 9900 & 11200 & 10100 & 9900 \\
\hline Case No. 3 & 13100 & 9900 & 11200 & 12300 & 14200 \\
\hline Case No. 4 & 11700 & 12400 & 12000 & 9900 & 10500 \\
\hline Case No. 5 & 11700 & 12400 & 12000 & 9900 & 10500 \\
\hline Case No. 6 & 11100 & 12300 & 12700 & 13200 & 14300 \\
\hline Case No. 7 & 14900 & 16200 & 15000 & 15400 & 15500 \\
\hline Case No. 8 & 15000 & 10300 & 16600 & 12400 & 14600 \\
\hline Mean & $\mathbf{1 2 3 6 3}$ & $\mathbf{1 1 9 5 0}$ & $\mathbf{1 2 4 7 5}$ & $\mathbf{1 2 7 8 8}$ & $\mathbf{1 3 1 2 5}$ \\
\hline S.E \pm & $\mathbf{9 3 4 . 4 5}$ & $\mathbf{7 3 1 . 1 9}$ & $\mathbf{8 3 5 . 9 7}$ & $\mathbf{8 5 8 . 8 7}$ & $\mathbf{7 0 4 . 0 1}$ \\
\hline
\end{tabular}


Table.4 Platelate values observed in the present study are given in following table

\begin{tabular}{|c|c|c|c|c|c|}
\hline Platelet & Before & 7 Days & 21 Days & 45 Days & 60 Days \\
\hline Case No.1 & 261000 & 249000 & 210000 & 320000 & 312000 \\
\hline Case No. 2 & 220000 & 250000 & 280000 & 250000 & 270000 \\
\hline Case No. 3 & 331000 & 280000 & 320000 & 240000 & 320000 \\
\hline Case No. 4 & 268000 & 310000 & 280000 & 229000 & 257000 \\
\hline Case No. 5 & 271000 & 205000 & 236000 & 221000 & 270000 \\
\hline Case No. 6 & 263000 & 280000 & 230000 & 240000 & 280000 \\
\hline Case No. 7 & 256000 & 261000 & 267000 & 252000 & 252000 \\
\hline Case No. 8 & 246000 & 298000 & 285000 & 260000 & 280000 \\
\hline Mean & $\mathbf{2 6 4 5 0 0}$ & $\mathbf{2 6 6 6 2 5}$ & $\mathbf{2 6 3 5 0 0}$ & $\mathbf{2 5 1 5 0 0}$ & $\mathbf{2 8 0 1 2 5}$ \\
\hline S.E \pm & $\mathbf{1 1 0 8 8 . 9 3}$ & $\mathbf{1 1 6 8 0 . 1 7}$ & $\mathbf{1 2 6 4 3 . 4 6}$ & $\mathbf{1 0 7 4 7 . 0 9}$ & $\mathbf{8 5 9 4 . 9 2}$ \\
\hline
\end{tabular}

Table.5 The alkaline phosphatase values observed in the present study

\begin{tabular}{|c|c|c|c|c|c|}
\hline ALP & Before & 7 Days & 21 Days & 45 Days & 60 Days \\
\hline Case No.1 & 78.2 & 239 & 433.2 & 690.3 & 188 \\
\hline Case No. 2 & 88 & 386 & 720.1 & 843.6 & 431.2 \\
\hline Case No. 3 & 124 & 343.12 & 613 & 646 & 214 \\
\hline Case No. 4 & 49 & 229 & 489 & 339 & 131 \\
\hline Case No. 5 & 64.34 & 365 & 601 & 176 & 57.93 \\
\hline Case No. 6 & 156.9 & 373.3 & 516.1 & 643.2 & 240 \\
\hline Case No. 7 & 156 & 1294.3 & 398.3 & 247.7 & 154. \\
\hline Case No. 8 & 221 & 351 & 1354 & 543.3 & 313.5 \\
\hline Mean & $\mathbf{1 1 7 . 1 8}$ & $\mathbf{4 4 7 . 5 9}$ & $\mathbf{6 4 0 . 5 8}$ & $\mathbf{5 1 6 . 1 4}$ & $\mathbf{2 1 6 . 2 4}$ \\
\hline S.E \pm & $\mathbf{2 0 . 5 8}$ & $\mathbf{1 2 2 . 8 0}$ & $\mathbf{1 0 8 . 3 8}$ & $\mathbf{8 3 . 4 9}$ & $\mathbf{4 0 . 7 9}$ \\
\hline
\end{tabular}

Table.6 The Serum Cortisol values observed in the present study

\begin{tabular}{|c|c|c|c|c|c|}
\hline Cortisol & Before & 7 Days & 21 Days & 45 Days & 60 Days \\
\hline Case No.1 & 42.69 & 42.7 & 42.1 & 42.09 & 42.01 \\
\hline Case No. 2 & 49.25 & 46.3 & 49.3 & 45.1 & 47.3 \\
\hline Case No. 3 & 41.4 & 42.2 & 41.6 & 41 & 40.2 \\
\hline Case No. 4 & 25 & 25.5 & 25.9 & 25 & 25 \\
\hline Case No. 5 & 26.8 & 26 & 26 & 25 & 26.96 \\
\hline Case No. 6 & 26.3 & 26.6 & 26.2 & 26.3 & 26.1 \\
\hline Case No. 7 & 32.1 & 30.2 & 31.1 & 31.7 & 32 \\
\hline Case No. 8 & 41.6 & 41.8 & 42.1 & 42.2 & 42.4 \\
\hline Mean & $\mathbf{3 5 . 6 4}$ & $\mathbf{3 5 . 1 6}$ & $\mathbf{3 5 . 5 3}$ & $\mathbf{3 4 . 7 9}$ & $\mathbf{3 5 . 2 4}$ \\
\hline S.E \pm & $\mathbf{3 . 2 5}$ & $\mathbf{3 . 1 3}$ & $\mathbf{3 . 2 8}$ & $\mathbf{3 . 0 6}$ & $\mathbf{3 . 0 8}$ \\
\hline
\end{tabular}




\section{Packed Cell Volume}

The packed cell volume values in the present study are given in following table

No significant changes in Packed Cell Values were observed I throughout monitoring period of 60 days. Similar observations were also reported by Bhalerao (2010), Coutinho (2012) and Rajhans (2013) in dogs

No significant changes were observed in mean total White Blood Cells $(\mathrm{cmm})$ values throughout monitoring period of 60 days.

\section{Platelets}

No significant changes were observed in the mean total platelet throughout monitoring period of 60 days.

\section{Biochemical study}

Alkaline phosphatise and cortisol levels were estimated before surgery as well as on $7^{\text {th }}$, $21^{\text {st }}, 30^{\text {th }}, 45^{\text {th }}$ and $60^{\text {th }}$ day post operatively.

\section{Alkaline Phosphatase}

The alkaline phosphatase values observed in the present study were as follows

The mean total alkaline phosphatase values were $117.18 \pm 20.58,447.59 \pm 122.80,640.58$ $\pm 108.38,516.14 \pm 83.49$ and $216.24 \pm 40.79$, respectively the mean alkaline phosphatase increased significantly up to 45 days and subsequently it decreased and came to normal levels up to 60 days. Alkaline phosphatase is an enzyme which is important in the process of biomineralization. The increase in serum alkaline phosphatase after surgery upto 45 days could be attributed to increased osteoblastic activity, fibrous tissue formation at the fracture site, which assists in mineralization of soft callus. These observations are corroborating with the findings of Singh et al., (1976), Meller et al., (1984) and Coutinho (2012).

\section{Serum Cortisol}

The Serum Cortisol values observed in the present study were as follows

The mean Cortisol values were $35.64 \pm 3.25$, $35.16 \pm 3.13,35.53 \pm 3.28,34.799 \pm 3.06$ and $35.24 \pm 3.08$, respectively. In the present study the mean cortisol values (nmol /L) estimated before surgery were higher but later on, the non-significant decrease in mean serum cortisol values was during monitoring period was observed and were normalized on 60 days. Coutinho (2012) reported that there is decrease in mean cortisol level in all the cases of bone plating in dogs.

\section{References}

Ayyappan, S., Shiju S. M., Das B. C. 2, Prasad A. A. and Suresh Kumar, R. (2011) Management of diaphyseal humeral fracture using plate rod technique in a dog. Tamilnadu J. Veterinary \& Animal Sciences 7 (1): 35-38.

Bhagat, V. T. (200) Evaluation of limited contact dynamic compression plating for correction of diaphyseal fractures of long bones in dogs. M. V. Sc. thesis submitted to Tamil Nadu Veterinary and Animals Sciences University.

Bhalerao, D. V. (2010) Comparative studies on plate-rod construct and bone plating for long bone fractures in canines. Unpublished M. V. Sc. Thesis submitted to Maharashtra Animal and Fisheries Sciences University, Nagpur, Maharashtra.

Chavan, S. R. (2013) Evaluation of locking compression plate system for long bone fracture repair in dogs: A clinical study. 
M. V. Sc. thesis submitted to Maharashtra Animal and Fishery Sciences University, Nagpur, India.

Coutinho, N. R. (2012) Evaluation of interlocking nail for long bone fracture repair in dogs: a clinical study. Unpublished M. V. Sc. Thesis Maharashtra Animal and Fishery Science University, Nagpur.

Ferry K. A., D. Fawcett, W. Gentry, Hyman, S. Geller and M. Slater (2000) Effect of intramedullary pin size on reducing bone plate strain. Vet Comp Ortho Traumatol 13 (4):185-190.

Guillemot A. E., F. G. Asimus and J. F. Vacher (2002) Biological osteosynthesis of communitted femoral fracture in a cat using a pin/ VCP plate combination. Prat. Med. Chir. Anim. Comp. 37:211-214.

Gupta, P. (2005). Use of interlocking nails for repair of humeral and tibial shaft fractures under image intensifier in dogs. M. V. Sc. thesis submitted to Anand Agricultural University.

Hulse D. W., M. N. Hyman and M. Slater (1997) Reduction in plate strain by addition of intramedullary pin, Veterinary surgery 26:451-459.

Kaur, H. (2011) Studies on locking compression $\mathrm{T}$ plates and cross pinning for fixation of proximal /distal third long bone fractures in canines. M. V. Sc. thesis submitted to Guru Anged Dev Veterinary and Animal Sciences University, Ludhiana, India.

Meller Y., R. S. Kestenbaum, M. Mozes, G. Mozes, R. Yagil and S. Shany (1984) Mineral and endocrine metabolism during fracture healing in dogs. Clin Orthop Realt Research 187:289-95.

Patil, S.N. (2007) Studies on healing of fractures of femur in canine with special reference to use of different Implants and anabolic hormone (a cl|nical study). Unpublished Ph.D. Thesis submitted to Maharashtra Animal and Fisheries Sciences University, Nagpur, Maharashtra

Rajhans, M.S. (2013) Stabilization of splinters of long bone fracture in canines. M. V.Sc thesis submitted to NDVSU, Jabalbur.

Roe, S. (2004). Internal fracture fixation. In: Textbook of Small Animal Surgery, Slatter, D. H. 3rd Ed, Vol. II. WB Saunders, Philadelphia. Pp: 1798-1818.

Singh, H., J. E. Lovell, A. G. Schiller and G. H. Kenner (1976) Serum Calcium, Phosphorus and Alkaline Phosphatase levels in dogs during experimental repair of ulnar defects. Indian Vet. J. 53: $862-865$.

\section{How to cite this article:}

Yadav G. U., L. B. Sarkate and Lokhande D. U. 2021. Haematological Studies in the Dogs Having Long Bone Fractures Treated with Plate Rod Construct. Int.J.Curr.Microbiol.App.Sci. 10(04): 787-793. doi: https://doi.org/10.20546/ijcmas.2021.1004.081 